\title{
Solid Lipid Nanoparticles of $p$-hexanoyl calix[4]arene as a controlling agent in the photochemistry of a sunscreen blocker
}

Michaela Pojarova, Gennady S. Ananchenko, Konstantin A. Udachin, Malgosia Daroszewska, Florent Perret, Anthony W. Coleman, and John A. Ripmeester

\section{Supporting Information}

Materials. $p$-Hexanoyl calix[4]arene was synthesized according to the procedure, previously described.[1] Solvents and reagents were purchased from Aldrich and used as supplied.

Crystals of the complex $2 \mathrm{C} 6 \mathrm{OH} \cdot 1 \mathrm{t}$-EHMC were prepared by dissolving $3.0 \mathrm{mmol}$ of $\mathrm{C} 6 \mathrm{OH}$ and $75 \mathrm{mmol}$ of $t$-EHMC in $10 \mathrm{ml}$ of hot ethanol. The solution was placed into a stove preheated at $75^{\circ} \mathrm{C}$ and the solvent was allowed to slowly evaporate until the crystals have been formed. Then, the solution was slowly $\left(10^{\circ} \mathrm{C} /\right.$ day $)$ cooled down, the crystals were separated and rinsed with cold methanol.

In order to check a possible analogy with $2 \mathrm{C} 6 \mathrm{OH} \cdot 1 t$-EHMC, we have grown crystals of $\mathrm{C} 6 \mathrm{OH} \cdot t$ EHMC from neat $t$-EHMC by the guest displacement method [2]. $200 \mathrm{mg}$ of $\mathrm{C} 6 \mathrm{OH}$ were dissolved in $3 \mathrm{ml}$ of chloroform, and $2 \mathrm{ml}$ of $t$-EHMC were added. The solution was placed in a stove preheated at $75^{\circ} \mathrm{C}$ and chloroform was allowed to slowly evaporate until the crystals have been formed (ca. 3 days). The mixture was kept at this temperature for additional 5 days to complete displacement of $\mathrm{CHCl}_{3}$ by $t$-EHMC in calixarene capsules. After cooling down to room temperature, the crystals were separated and rinsed several times with cold methanol. TGA analysis showed the composition of the complex as $2 \mathrm{C} 6 \mathrm{OH} \cdot 1.4 t$-EHMC. UV irradiation of this material (under the same reaction conditions as described below) revealed a similar to SLN composition of the mixture and the appearance of both truxinates after the photolysis. The quality of the crystals of this new complex did not allow us to solve the X-ray diffraction data precisely but the information on the symmetry $\left(\mathrm{P} 2{ }_{1} / \mathrm{n}\right)$ and the capsular nature of the complex was found to be in agreement.

The SLN were prepared according to ref.[3]. C6OH (5mg/ml THF) and $t$-EHMC (molar ratio 1:1 and 2:1)) were dissolved in tetrahydrofuran. Under magnetic stirring, in a round flask, to a volume of $3 \mathrm{ml}$ of the solution, $100 \mathrm{ml}$ of pure water (resistivity > $18 \mathrm{M} \Omega$ ) was added at a constant flow rate of $300 \mathrm{ml} / \mathrm{min}$. The slightly milky suspension was stirred for an additional 
minute. After evaporation of the solvent under vacuum the final volume was reduced to the half. The suspension was divided into product trays and freeze-dried.

Characterization of complexes. Thermogravimetric (TGA) and differential scanning calorimetry (DSC) analyses were performed on TA Instruments devices with temperature ramp of $3^{\circ} \mathrm{C} / \mathrm{min}$.

Single crystal X-ray diffraction data were collected in the $\omega-2 \Theta$ scan mode on a Bruker Smart diffractometer equipped with a CCD detector using graphite-monochromatized MoK $\alpha$ radiation $(\lambda=0.71073 \AA)$. The crystal structure of $2 \mathrm{C} 6 \mathrm{OH} \cdot 1 t$-EHMC was solved by direct methods and refined by full-matrix least squares on $\mathrm{F}^{2}$ using the SHELXTL suite of programs. Positions of the disordered atoms were found directly from the maps of residual electron density. The distances and angles for the disordered chains were fixed and the site occupancies were refined for the different parts with the same thermal parameters for the same atoms in the various fragments. At the end of the refinement, all site occupancies were fixed and hydrogen atoms were placed into calculated positions. The summary of XRD-data is given in the Table.

The PXRD data were collected on Advanced diffraction system X2 by Scintag Instruments and on a Bruker AXS powder diffractometer operating at $\mathrm{CuK} \alpha 1, \lambda=1.540562 \AA$.

Solution NMR spectra were recorded on a Bruker DRX 400 NMR spectrometer in $\mathrm{CDCl}_{3}$ solution. ${ }^{13} \mathrm{C}$ CP-MAS solid state NMR spectra were taken on Bruker AMX 300 instrument.

Photolysis. Photolysis of solids was carried out on a Novacure 2100 spot curing system in UV range of $320-390 \mathrm{~nm} .10 \mathrm{mg}$ of powders of complexes or SLN were equally distributed over an area of ca. $3 \mathrm{~cm}^{2}$ in the bottom of a vial. The vial was placed in water to avoid overheating of samples during UV irradiation. The distance between the edge of the light guide and the samples was $5 \mathrm{~cm}$. The light intensity $2500 \mathrm{~mW} / \mathrm{cm}^{2}$ was applied.

The SDS micellar solution of $t$-EHMC was prepared by stirring $0.8 \mathrm{mmol}(232 \mathrm{mg})$ of $t$-EHMC with $100 \mathrm{ml}$ of $0.1 \mathrm{M} \mathrm{SDS}$ in water for $24 \mathrm{hrs}$ under nitrogen. The formed clear solution was placed in a quartz tube and was irradiated in Rayonet photoreactor equipped with $300 \mathrm{~nm}$ bulbs at ca. $40{ }^{\circ} \mathrm{C}$ for $48 \mathrm{hrs}$. After saturating the solution with $\mathrm{NaCl}$ to salt the SDS out, the products were extracted by $\mathrm{CHCl}_{3}$, washed with water and dried with $\mathrm{Na}_{2} \mathrm{SO}_{4}$. Evaporation of the solvent gave a complex mixture of products, which was separated by preparative HPLC on a Waters Delta Prep 4000 with column Novapac C18 19x300 mm, solvent 80\% methanol (flow 36 ml $/ \mathrm{min}$ ) for $26 \mathrm{~min}$, then gradient to $90 \%$ for 9 min was applied. The fraction with retention time $39.1 \mathrm{~min}$ was collected and another fraction with retention time 41.6 min was chromatographed again on 
the same column using $88 \%$ acetonitrile (flow $35 \mathrm{ml} / \mathrm{min}$ ) as a solvent. The fraction with retention time 13.5 min was collected.

HPLC-MS analysis was performed on a Waters Alliance 2795 / ZQ 2000 instrument with ES+ detection; the column Sunfire C18 2.1x100 mm, solvent $90 \% \mathrm{CH}_{3} \mathrm{CN}$ with $0.01 \%$ formic acid. ${ }^{1} \mathrm{H}$ NMR (400 MHz, $\mathrm{CDCl}_{3}$ ) data of isolated cyclobutanes:

$\beta$-truxinate (i.e. syn isomer): 6.85 (quasi d, 4H, J=8.5 Hz), 6.67 (quasi d, 4H, J=8.5 Hz), 4.28 (quasi d, 2H, J=6.3 Hz, 2CH in cyclobutane), $4.04\left(\mathrm{~m}, 4 \mathrm{H}, 2 \mathrm{CH}_{2} \mathrm{O}\right.$ ), 3.74 (quasi d, 2H, J=6.3 Hz, $2 \mathrm{CH}$ in cyclobutane), $3.72\left(\mathrm{~s}, \mathrm{CH}_{3} \mathrm{O}\right), 1.6(\mathrm{br}, 2 \mathrm{H}, \mathrm{CH}), 1.3\left(\mathrm{br} \mathrm{m}, 16 \mathrm{H}, 8 \mathrm{CH}_{2}\right), 0.88$ (t, J=7.3 Hz, $\left.4 \mathrm{CH}_{3}\right)$

$\delta$-truxinate (i.e. anti isomer): 7.21 (quasi d, 4H, $\mathrm{J}=8.5 \mathrm{~Hz}$ ), 6.85 (quasi d, 4H, J=8.5 Hz), 4.05 (m, $4 \mathrm{H}, 2 \mathrm{CH}_{2} \mathrm{O}$ ), 3.80 (s, $\mathrm{CH}_{3} \mathrm{O}$ ), 3.60 (quasi d, $2 \mathrm{H}, \mathrm{J}=9.1 \mathrm{~Hz}, 2 \mathrm{CH}$ in cyclobutane), 3.40 (quasi d, $2 \mathrm{H}, \mathrm{J}=9.1 \mathrm{~Hz}, 2 \mathrm{CH}$ in cyclobutane), 1.55 (br, 2H, CH), 1.3 (br m, 16H, 8CH2), 0.90 (t, J=7.3 Hz, $\left.2 \mathrm{CH}_{3}\right), 0.87\left(\mathrm{t}, \mathrm{J}=7.3 \mathrm{~Hz}, 2 \mathrm{CH}_{3}\right)$.

\section{References for Supporting Information}

[1] Shahgaldian, P.; Coleman, A. W.; Kalchenko, V. I. Tetrahedron Lett. 2001, 42, 577

[2] Ananchenko, G. S.; Udachin, K. A.; Dubes, A.; Ripmeester, J. A.; Perrier, T.; Coleman, A. W. Angew. Chem. Int. Ed., 2006, 45, 1585

[3] Shahgaldian, P.; de Silva, E.; Coleman, A. W. J. Incl. Phenom. Macrocycl. Chem. 2003, 46, 175. Shahgaldian, P.; Gualbert, J.; Aïssa, K.; Coleman, A. W. Eur. J. Pharm. Biopharm. 2003, $55,181$. 


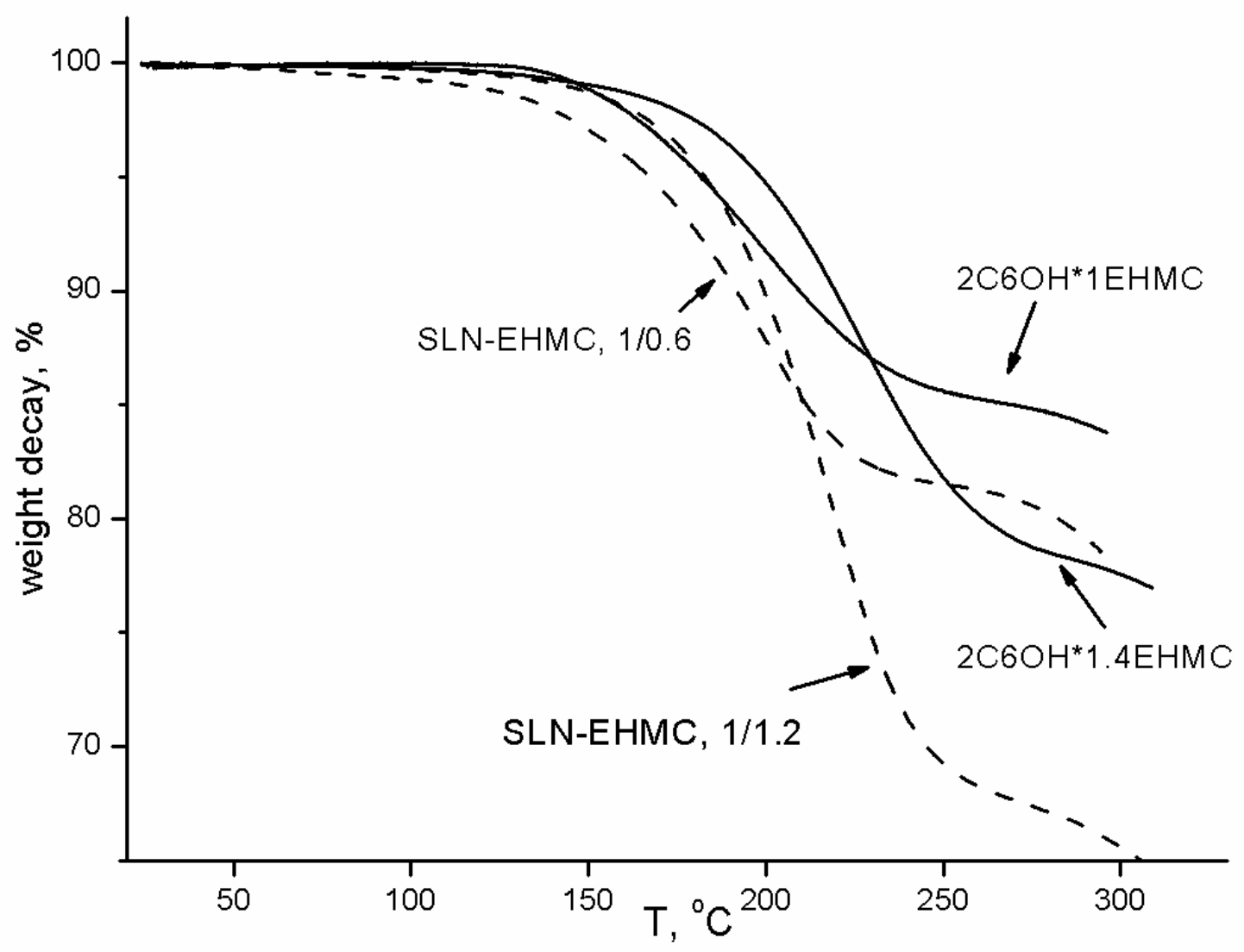

Figure S1. TGA of inclusion complex 2C6OH-1t-EHMC and SLN loaded with $t$-EHMS: SLNEHMC $1 / 0.6$ and 1/1.2. 


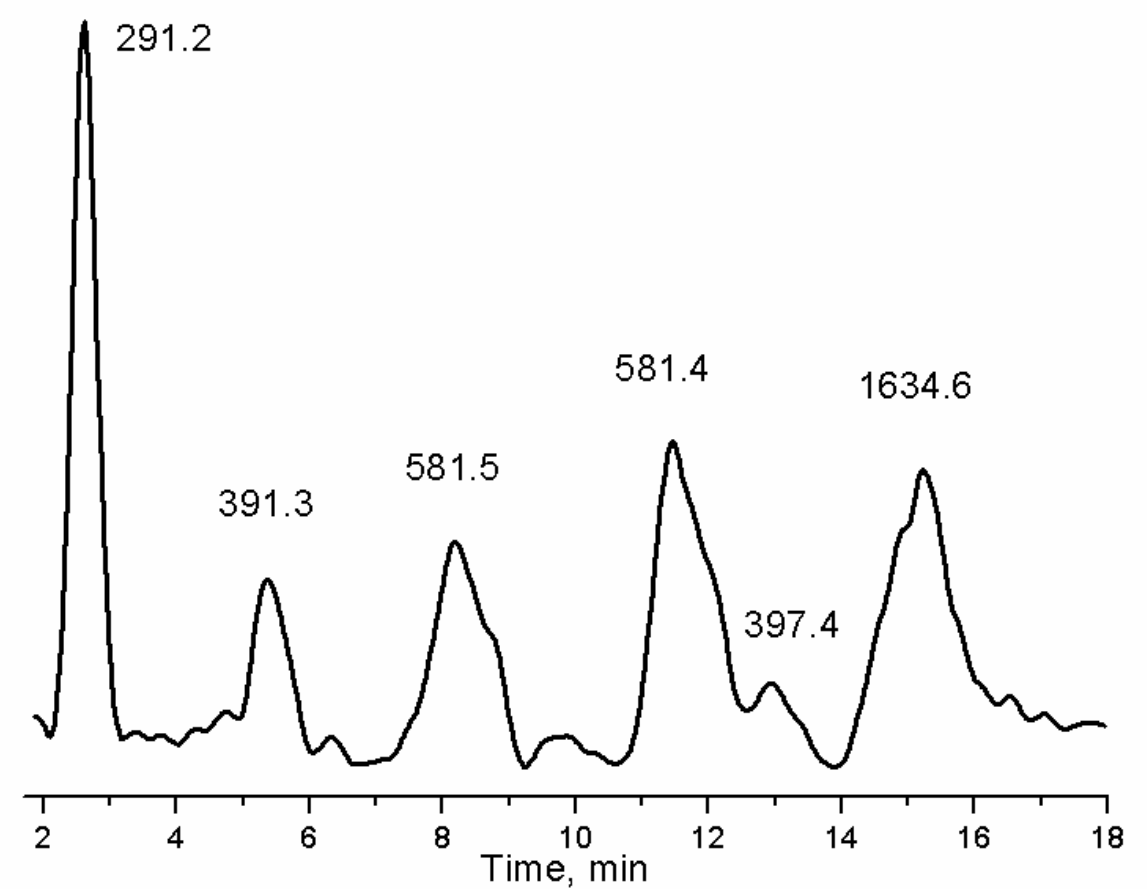

Figure S2. HPLC-MS (ES+) of the irradiated SLN-EHMC. cis and trans- EHMC (M=291.2) were not resolved under these conditions; the calixarene is detected as a dimer $(M=1634.6)$. Products with $\mathrm{M}=581.4$ and 581.5 are the corresponding truxinates - products of photodimerisation of EHMC. The minor products with $\mathrm{M}=391.3$ and 397.4 have not been identified. 